\title{
Performance of mechanical biological treatment of residual municipal waste in Poland
}

\author{
Emilia den Boer ${ }^{1, *}$, and Andrzej Jędrczak ${ }^{2}$ \\ ${ }^{1}$ Wrocław University of Science and Technology, Faculty of Environmental Engineering, Wybrzeże \\ Wyspiańskiego 27, 50-370 Wrocław, Poland \\ ${ }^{2}$ University of Zielona Góra, Faculty of Civil Engineering, Architecture and Environmental \\ Engineering, ul. Prof. Z. Szafrana 1, 65-516 Zielona Góra, Poland
}

\begin{abstract}
The number and capacity of mechanical-biological treatment (MBT) plants in Europe increased significantly in the past two decades as a response to the legal obligation to limit the landfilling of biodegradable waste in landfills and to increase recycling and energy recovery from waste. The aim of these plants is to prepare residual municipal waste for recovery and disposal operations, including especially separation and stabilization of the easily biodegradable fraction (the biofraction). The final products of MBP technology are recyclables, stabilate, high calorific fraction which is used for the production of refuse derived fuel (RDF) and the remaining residual fraction. The shares of the output fractions, especially of the recyclables and RDF determine the overall efficiency of MBT technology in diverting waste from landfills. In this paper results of an assessment of one exemplary MBT plant are provided. The analysis was performed within a comparative study in which 20 selected MBT plants in Poland were subject to a detailed analysis, focusing, both at the design parameters as well as operational ones. The selected plant showed relatively higher overall materials recovery efficiency. With the view to circular economy targets, increased automation of the mechanical waste treatment will be required to support achieving high level diversion from landfills. The study reviled that stabilisation of biofraction should be improved by a better control of process conditions, especially moisture content.
\end{abstract}

\section{Introduction}

Majority of the municipal residual waste in Poland is treated in regional mechanicalbiological treatment (MBT) plants. There are 127 regional MBP plants with combined mechanical processing capacity of approximately 9.4 million $\mathrm{Mg} /$ year, and the biological about 4.1 million $\mathrm{Mg}$ /year. The total amount of municipal waste collected in Poland in 2015 was 10863 thous. $\mathrm{Mg}$, of which 8326 thous. $\mathrm{Mg}$ was collected as residual waste [2]. Approximately 8250 thous. $\mathrm{Mg}$ of residual waste was treated in MBT plants. In the period 2015-2016 six new incineration plants have been commenced with the total capacity of

\footnotetext{
*Corresponding author: emilia.denboer@pwr.edu.pl
} 
974 thous. Mg/year. As the summary capacity of MBT plants and waste incinerators exceeds the amount of residual waste, which is decreasing due to rising levels of separate collection, the competition on the waste market becomes severe. The main purpose of the MBT technology is to recover materials for recycling and energy recovery and to stabilise the biodegradable waste before landfilling. In Poland the MBT plants accept both the residual waste as well as separately collected waste to sort and prepare it for recycling.

\subsection{Requirements of MBT technology}

\subsubsection{Mechanical treatment}

Mechanical processing of mixed municipal waste is aimed at separating fractions for material and/or energy use, and the fraction requiring further biological treatment. Waste generated in the process of mechanical treatment of residual municipal waste are to be processed in accordance with the waste hierarchy. The fraction of at least $0-80 \mathrm{~mm}$ needs to be separated and stabilised in the biological part of a MBT plant, which can be conducted under aerobic or anaerobic conditions. Three types of biological treatment are defined: aerobic stabilization, anaerobic stabilisation and biodrying.

\subsubsection{Biological treatment}

The biostabilisation under aerobic conditions is carried out in accordance with the following requirements: waste is processed, including turning of the waste, for a period of 8 to 12 weeks in total; for at least two first weeks the process takes place in a closed reactor or in the hall, with active aeration and prevention of the entry of untreated process air to the atmosphere, until reaching the respiration activity $\left(\mathrm{AT}_{4}\right)$ value of less than $20 \mathrm{mg} \mathrm{O}_{2} / \mathrm{g}$ dry mass $(\mathrm{dm})$. The process is continued in open windrows (maturation) until AT4 reaches $<10 \mathrm{mg} \mathrm{O}_{2} / \mathrm{g} \mathrm{dm}$.

The biostabilisation under anaerobic conditions is carried out in two stages:

- in the first stage mesophilic fermentation for at least 20 days or thermophilic fermentation for at least 12 days needs to be carried out

- in the second stage aerobic stabilization in a closed reactor or in the hall, with active aeration for at least two weeks should be carried out. It is allowed to carry out the second stage in the open windrows, while waste should aerated by turning at least once a week, for at least 3 weeks.

The biodrying is carried out under aerobic conditions, with active aeration in the closed reactor or hall for at least 7 days. The aim of biodrying is to reduce the moisture content of waste in order to improve the calorific value of the combustibles, which are used for the refuse derived fuel (RDF) production.

\subsection{The challenges of the European circular economy}

The circular economy package, adopted by the Commission on 2 December 2015, includes legislative proposals on waste [3], with long term targets to reduce landfilling and increase recycling and reuse. The targets set for municipal waste are very ambitious, including:

- a common EU target for recycling $65 \%$ of municipal waste by 2030 ;

- a common EU target for recycling $75 \%$ of packaging waste by 2030 ;

- a binding landfill target to reduce landfill to maximum of $10 \%$ of municipal waste by 2030 . 
Those targets have already been incorporated to the newly adopted National Waste Management Plant (KPGO2022) [1]. In Poland in 2015 only $23.3 \%$ of municipal waste collected separately [2]. The recycling level of the total municipal waste in 2015 amounted to $26.4 \%$. From the past data it is clear that increase of the separate collection levels progresses very slowly in Poland. It is certain that accomplishment of the required recycling levels will require both actions - improving the separate collection rates and enhancing recovery of recyclables from residual waste. This can be done with help of modern sorting technologies which are applied in the Polish MBP plants. The national waste management plan stipulates that energy recovery should not exceed $30 \%$ of the total mass of municipal waste. Moreover the regional plans assume that landfilling rate of MBT residues should be limited to $30 \%$ of the plant input.

In this paper technology used in one of more advanced MBT plants in Poland is presented. Efficiency of the plant is assessed in the context of the future recycling targets and the obligation to divert waste from landfills. The results presented here are based on a large scale study of 20 MBT installations in Poland commissioned by the General Directorate for Environmental Protection [4].

\section{Selected MBT plant}

The MBT plant „Eko-MAZURY” Sp. z o.o in Siedliska has been selected for a detailed presentation and analysis in this paper, due to its relatively high technological advancement, and high score in the overall performance assessment. The plant is located in the north-eastern part of Poland. It receives municipal waste from the area of 12 communes, with the total population of 159 thousand people. The capacity of the mechanical part of the plant is $59000 \mathrm{Mg}$ and of the biological part - $19000 \mathrm{Mg}$ per year.

The MBT process takes place in two basic technological facilities: sorting hall and in the aerobic stabilization part. The aerobic stabilisation is conducted in two stages. The intensive stabilisation takes place in a concrete hall. The second stage - maturation takes place in open windrows. The technological scheme of the installation is shown in Fig. 1. The plant accepts both residual municipal waste and separately collected waste.

\subsection{Technology description}

\subsubsection{Mechanical treatment of waste}

Residual waste passes through a beg opener (BRT, type MSW2-13-15) or is loaded directly to the conveyor loading channel. Optionally waste can be shredded (KOMPTECH shredder). Waste is transported on a conveyor to the preselection cabin, where 6 people crew sorts our items, which are likely to hinder or disrupt the sorting process, i.e. construction waste, glass, cardboard boxes, large bags and waste foil, waste large metal and hazardous waste. From the preselection cabin waste is transported on the conveyor belt to the rotating sieve drum (length $12 \mathrm{~m}$, diameter $3.0 \mathrm{~m}$, SUTCO Polska), in which the splitting into two fractions takes place: the biofraction $(<80 \mathrm{~mm})$ and the coarse fraction ( $>80 \mathrm{~mm}$ ). The biofraction passes through a magnetic separator (Magnetix, type SNK120-130) for the separation of ferrous metals, and the final sorting cabin to separate the aluminum cans, PET bottles, films and other non-biodegradable waste before unloading it into the aerobic stabilization hall. 


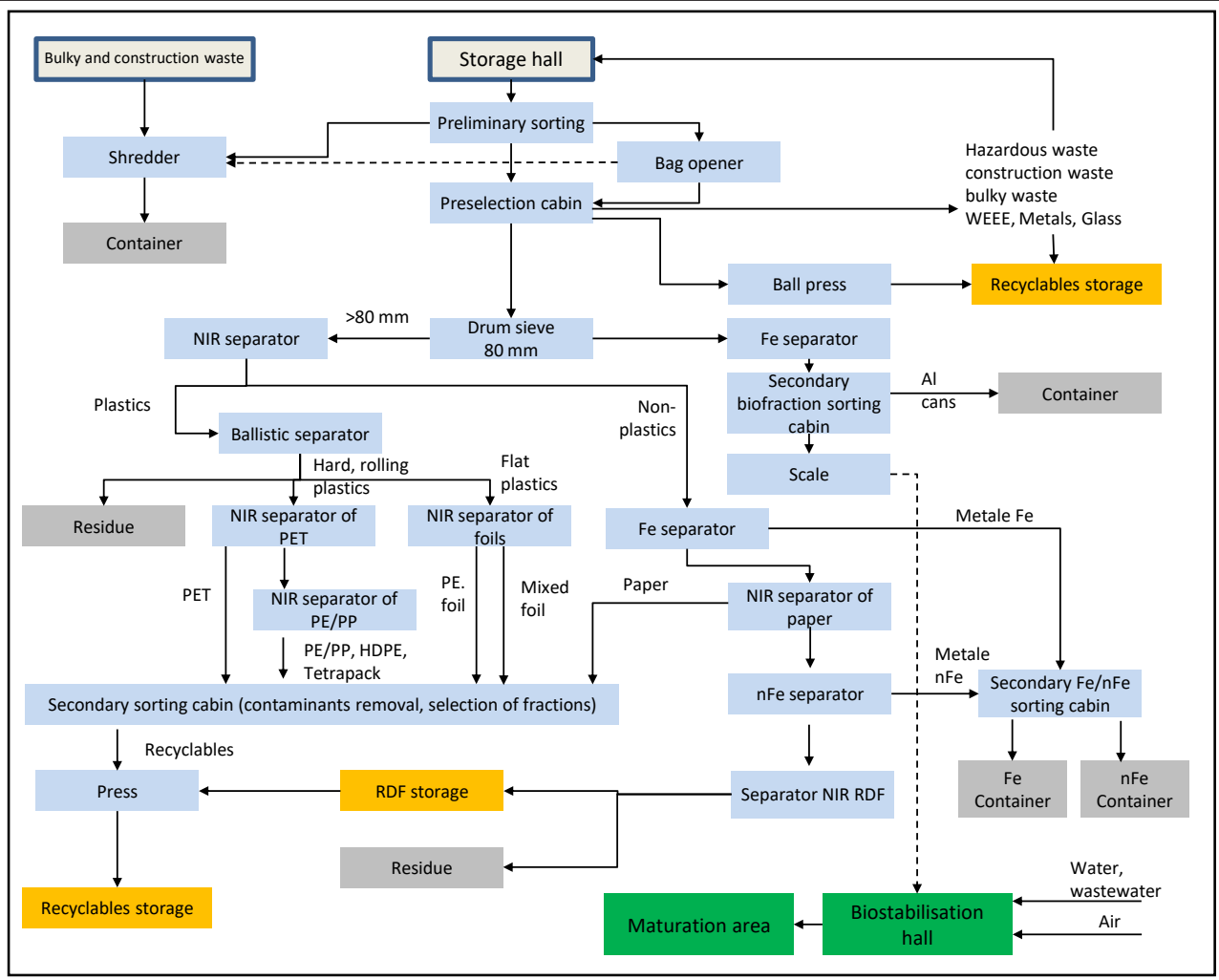

Fig. 1. Scheme of the MBT technology in Siedliska.

The coarse fraction $(>80 \mathrm{~mm})$ if fed to the further sorting process in order to recover recyclables and the high calorific fractions for waste derived fuel (RDF) production.the sorting line consists of the following devices: a near infra-red (NIR) optical separator (TITECH/TOMRA) to separate plastics; a ballistic separator to separate rotating and flate plastics (SUTCO Polska); five further NIR optical separators to sort out PET, foils, paper, $\mathrm{PP} / \mathrm{PE}$ and refuse derived fuel (pre-RDF); a magnetic separator for ferrous metals (Magnetix typ SNK120-130, and an eddy current separator for non-ferrous (mostly aluminium) metals (Magnetix typ SWP150). The automated separation is followed by the secondary (manual) sorting cabins (24 persons controlling the recyclables streams and 3 - the biofraction). The recyclables and pre-RDF fraction are transported to the channel press baler and transferred to external recycling/recovery companies. The remaining waste stream of coarse fraction $(>80 \mathrm{~mm})$ is gathered in the container and disposed of in a landfill. The whole sorting technology involves 69 conveyor belts with the total length of $800 \mathrm{~m}$.

\subsubsection{Biological treatment of waste}

The biofraction separated on a rotating screen $(<80 \mathrm{~mm})$ is subject to two stages biological processing: the intensive aerobic stabilization and maturation. The intensive aerobic stabilization is performed in a BIOFIX system comprising a closed hall with 4 tunnels (total capacity of $2920 \mathrm{~m}^{3}$ ) with an automatic loading system; an automatic waste turning machine (TOPTURNX 53); moistening with process water circulation system; forced aeration system and an automatic unloading mechanism for the stabilised waste. The process of intensive aerobic stabilization takes place within four weeks. The temperature 
range is $25-70^{\circ} \mathrm{C}$. The resulting stabililate (referred to as stabilate I) is discharged automatically on the outdoor maturation area. The maturation process takes from a few to several weeks until the required stability is reached (AT4 $<10 \mathrm{mg} \mathrm{O}_{2} / \mathrm{g} \mathrm{s.m}$.). The stabilate is screened on the mobile rotating screen. The fraction $<20 \mathrm{~mm}$ can be used for constructing the biological landfill cover (which is a recovery operation). The remaining stabilate is landfilled.

\section{Assessment of the overall technology performance}

Table 1 provides data on the volume of emissions and energy consumption by the plant operation, based on yearly average values. The wastewater is purified by a reverse osmosis technology. Waste gases pass through a water scrubber and a biofilter to remove part of the organic pollutants and mitigate odour problem. The biofilter surface is $-400 \mathrm{~m}^{2}$ and the yearly amount of air from stabilisation hall let though a biofilter is approx. 54820 thous. $\mathrm{m}^{3}$.

Table 1. Data on total emissions and energy consumption of the MBT plant.

\begin{tabular}{|c|c|c|c|}
\hline \multicolumn{2}{|c|}{ Media consumption } & \multicolumn{2}{c|}{ Emissions volume } \\
\hline $\begin{array}{c}\text { Electric energy, } \\
{[\mathrm{kWh} / \mathrm{Mg}]}\end{array}$ & $\begin{array}{c}\text { Water } \\
{\left[\mathrm{m}^{3} / \mathrm{Mg}\right]}\end{array}$ & $\begin{array}{c}\text { Wastewater } \\
{\left[\mathrm{m}^{3} / \mathrm{Mg}\right]}\end{array}$ & $\begin{array}{c}\text { Waste gases } \\
{\left[\mathrm{m}^{3} /(\mathrm{Mg} \cdot \mathrm{h})\right]}\end{array}$ \\
\hline 35 & 0.01 & 0.14 & 14.3 \\
\hline
\end{tabular}

The average composition of input waste (based on manual sorting analyses) is presented in Fig. 2.

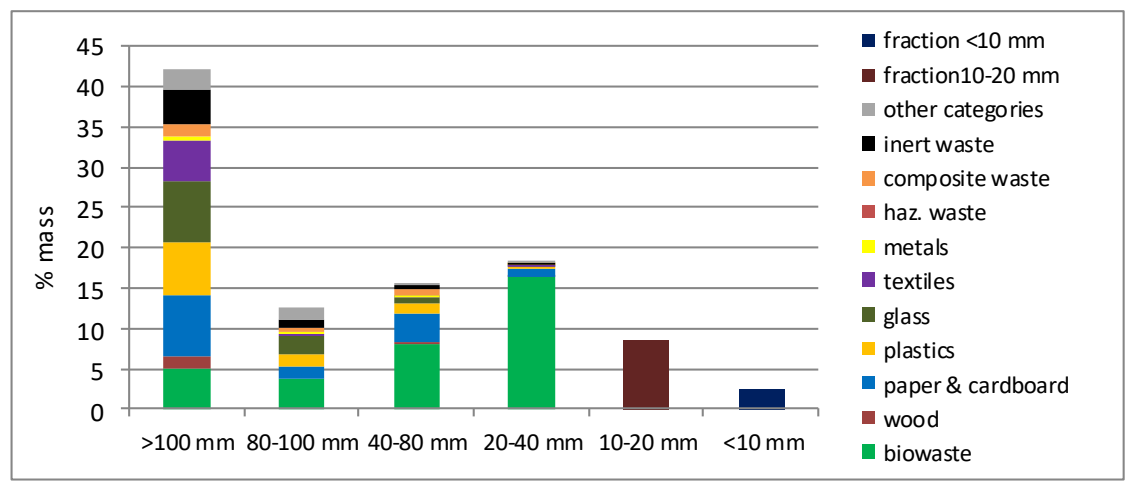

Fig. 2. Composition of input (residual) waste, based on [4].

From Fig. 2 it can be seen that biowaste is contained mainly in fraction $20-40 \mathrm{~mm}$ and to a lesser extent in fraction $40-80 \mathrm{~mm}$. Recyclables occur mainly in fractions $>100 \mathrm{~mm}$ and $80-100$. Paper is also present in fraction $40-80 \mathrm{~mm}$, however this is rather a low quality hygienic paper. Further characteristics of the input (residual) waste is provided in Table 2.

Composition of output waste fractions separated in the mechanical part of the plant the biofraction $(<80 \mathrm{~mm})$ and the residue of the coarse fraction $(>80 \mathrm{~mm})$, after passing through the sorting process, are presented in Fig. 3. The coarse fraction after sorting still contains a significant amount of plastics. The other materials include textiles and other categories of waste (mainly diaper and other hygiene items). 
Table 2. Characteristics of the Siedliska MBT plant input waste.

\begin{tabular}{|c|c|c|c|c|c|c|c|}
\hline & \multicolumn{6}{|c|}{ Size fraction [mm] } & \multirow{2}{*}{$\begin{array}{l}\text { Overall } \\
\text { residual } \\
\text { waste }\end{array}$} \\
\hline & $<10$ & $10-20$ & $20-40$ & $40-80$ & $80-100$ & $>100$ & \\
\hline Recyclables content [\%] & 0.0 & 0.0 & 7.9 & 36.5 & 44.6 & 52.6 & 35.0 \\
\hline $\begin{array}{l}\text { Share of biodegradable } \\
\text { fractions }[\%]^{1)}\end{array}$ & $\begin{array}{c}47.9 \\
(15.7)\end{array}$ & $\begin{array}{l}75.3 \\
(30.2)\end{array}$ & $\begin{array}{l}95.4 \\
(0.4)\end{array}$ & $\begin{array}{l}77.7 \\
(4.1)\end{array}$ & $\begin{array}{l}43.8 \\
(5.6)\end{array}$ & $\begin{array}{l}39.1 \\
(2.0)\end{array}$ & $\begin{array}{l}60.7 \\
(1.6)\end{array}$ \\
\hline Moisture content $[\%]^{1)}$ & $\begin{array}{l}35.4 \\
(1.2)\end{array}$ & $\begin{array}{l}29.5 \\
(14)\end{array}$ & $\begin{array}{l}61.6 \\
(3.3)\end{array}$ & $\begin{array}{l}51.2 \\
(3.1)\end{array}$ & $\begin{array}{l}44.7 \\
(2.0)\end{array}$ & $\begin{array}{l}43.4 \\
(1.4)\end{array}$ & $\begin{array}{l}46.1 \\
(2.9)\end{array}$ \\
\hline $\begin{array}{l}\text { Loss of ignition [\% dry } \\
\text { mass] }]^{1)}\end{array}$ & $\begin{array}{l}36.9 \\
(2.4)\end{array}$ & $\begin{array}{c}30.7 \\
(14.4)\end{array}$ & $\begin{array}{l}64.2 \\
(4.2)\end{array}$ & $\begin{array}{l}70.8 \\
(2.8)\end{array}$ & $\begin{array}{l}80.0 \\
(2.1)\end{array}$ & $\begin{array}{l}84.4 \\
(2.5)\end{array}$ & $\begin{array}{l}70.2 \\
(5.0)\end{array}$ \\
\hline
\end{tabular}

${ }^{1)}$ standard deviation values in brackets

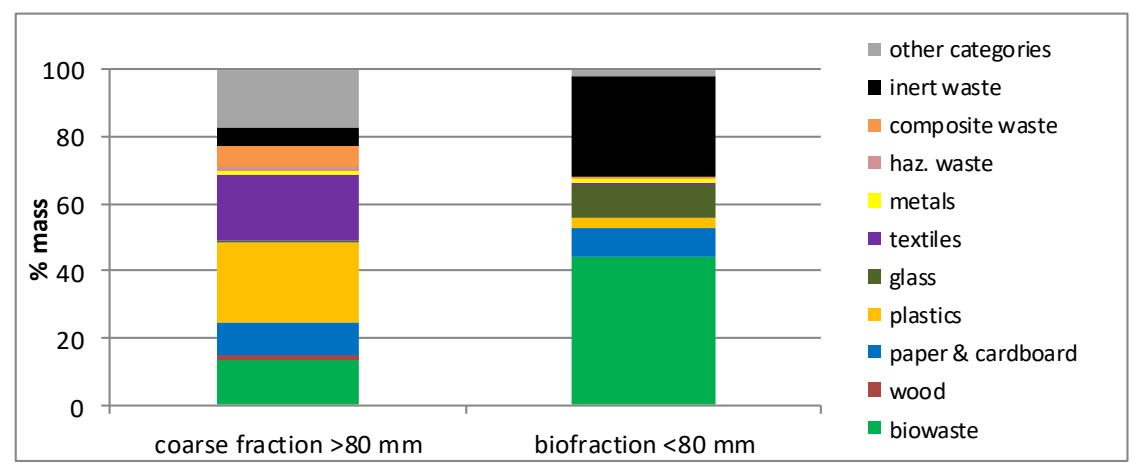

Fig. 3. Composition of the residual coarse fraction and the biofraction.

The destination of the residual coarse fraction is "other recovery" at external companies (e.g. energy recovery) or landfilling. Landfill acceptance criteria for this fraction include [5]: dissolved organic carbon (DOC) $<800 \mathrm{mg} / \mathrm{kg} \mathrm{dm}$; total dissolved solids (TDS) $<60 \mathrm{~g} / \mathrm{kg} \mathrm{dm}$ and the additional parameters (from January 2016): loss of ignition (LOI) $<8 \% \mathrm{dm}$; total organic carbon (TOC) $<5 \% \mathrm{dm}$; higher heating value (HHV) $<6 \mathrm{MJ} / \mathrm{kg}$ $\mathrm{dm}$. Properties of the coarse residues and the biofraction are presented in Table 3. The coarse fraction does not meet the current landfill acceptance criteria.

The biofraction is subject to two stage aerobic stabilisation. The stabilate after intensive stabilisation (stabilate I) and after maturation (stabilate II) has been analysed. Results are presented in Table 3. The acceptance criteria for stabilate at landfills are: 1) $\mathrm{AT} 4<10 \mathrm{mgO}_{2} / \mathrm{g} \mathrm{dm}$ or 2) $\mathrm{LOI}<35 \% \mathrm{dm}$ and $\mathrm{TOC}<20 \% \mathrm{dm}$ or 3 ) the loss of organic matter during stabilization measured by LOI or TOC must be greater than $40 \%$. Both stabilate I and stabilate II showed very low moisture content. Stabilate I fulfilled already the landfill acceptance criteria with respect to AT4, TOC and LOI. The organic matter loss during intensive stabilisation measured by LOI amounted to app. $24 \%$. The sample of stabilate II did not show any further progress in the decomposition rate. The reason for it was probably the very low moisture content, which hindered the microbiological activity. In some of the examined plants [4] the same problem was observed. The suboptimal process parameters hinder the stabilisation of the biofraction. On the other hand results of the analyses of the biofraction show rather low LOI and biodegradables content, which results in stabilate I meeting the landfill criteria. 
Table 3. Characteristics of the coarse fraction and biofraction separated in the MBT plant.

\begin{tabular}{|c|c|c|c|c|}
\hline & $\begin{array}{c}\text { Coarse } \\
\text { fraction } \\
>80 \mathrm{~mm}\end{array}$ & $\begin{array}{c}\text { Biofraction } \\
<80 \mathrm{~mm}\end{array}$ & Stabilate I & Stabilate II \\
\hline Recyclables content [\%] & 36.1 & 22.6 & & \\
\hline Share of biodegradable waste [\%] & 36.2 & 53.2 & & \\
\hline Moisture content [\%] & 44.6 & 30.8 & 24.0 & 25.7 \\
\hline LOI [\% dry mass] & 74.5 & 26.6 & 20.6 & 26.8 \\
\hline TOC [\% dry mass] & 42.2 & 16.3 & 12.6 & 14.3 \\
\hline HHV [MJ/kg dry mass] & 17.5 & & & 7.3 \\
\hline DOC in eluate [mg/kg dry mass] & 5460 & & & 3727 \\
\hline TDS in eluate [mg/kg dry mass] & 45990 & & & 38690 \\
\hline $\mathrm{AT}_{4}\left[\mathrm{mg} \mathrm{O}_{2} / \mathrm{g} \mathrm{dm}^{2}\right.$ & & & 4.0 & 3.8 \\
\hline $\mathrm{GB}_{21}\left[\mathrm{Ndm}^{3} / \mathrm{kg} \mathrm{dm}\right]$ & & & 10.3 & 11.5 \\
\hline $\mathrm{CH}_{4}[\% \mathrm{v} / \mathrm{v}]$ & & & 54.9 & 54.7 \\
\hline $\mathrm{CO}_{2}[\% \mathrm{v} / \mathrm{v}]$ & & & 43 & 43.2 \\
\hline
\end{tabular}

Fig. 4 shows the overall mass balance of the presented Siedliska MBT plant. The recyclables and the stabilate for land recultivation are waste fractions which are recovered from waste stream. The share of recyclables amounted to $11,0 \%$. Part of $>80 \mathrm{~mm}$ fraction is transferred to "other recovery" at external company (most likely for RDF production). The remaining stabilate, non-composted fractions and residual fraction $>80 \mathrm{~mm}$ were landfilled.

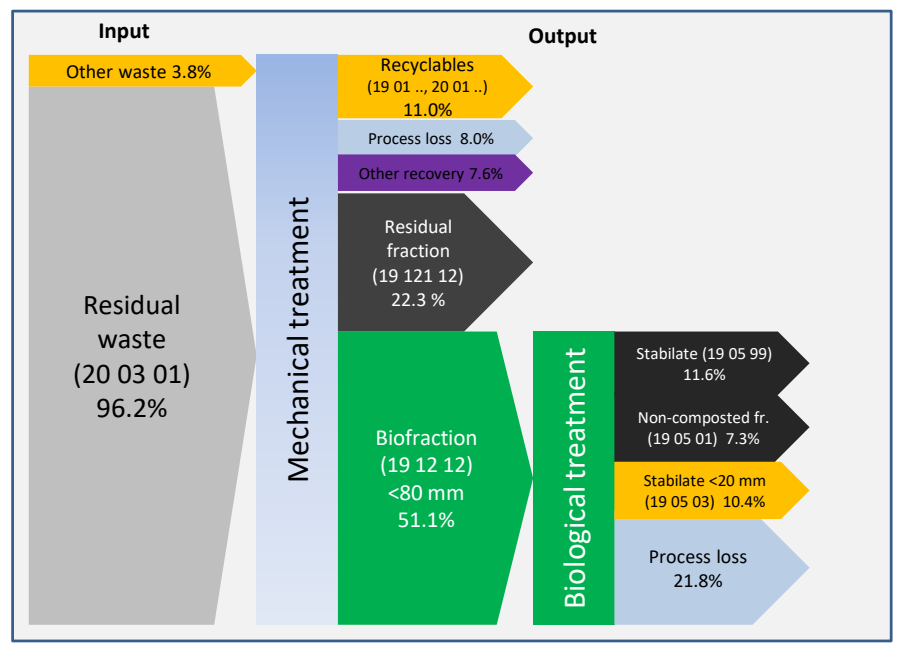

Fig. 4. Mass balance of residual waste treatment in the presented MBT plant.

\subsection{Performance of the Siedliska MBT plant against other MBP plants}

Mass balance of the Siedliska MBT plant against the other plants included in the assessment [4] is presented in Fig 5. Assessment of the overall efficiency of waste recovery in individual installations takes into account the shares of recycling, RDF recovery and landfilled waste in relation to the plant input. The average recycling rate of all plants was $6.1 \%$ (range: $0.04 \%-15.0 \%$ ). The plant in Siedliska showed second highest recycling rate 
$(11.0 \%)$. Analyses show that there is a clear correlation between the share of recycling and the number of mechanical devices per $10000 \mathrm{Mg}$ of the capacity of the plant [4].

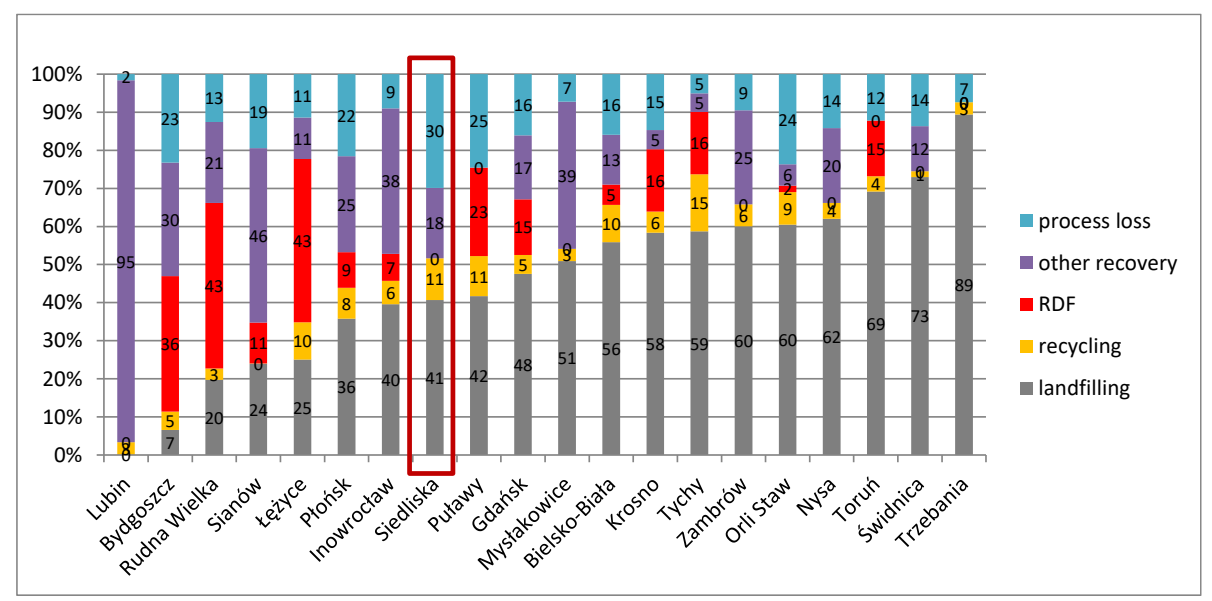

Fig. 5. Mass balance of the MBT plants included in the MBT comparative study [4].

The average share of RDF production is $12 \%(0-43 \%)$. The coarse fraction after separation of recyclables is used for RDF, however not in all plants. In some cases there is high share of "other recovery" (as in Siedliska plant). It includes the use of stabilate for land recultivation (normally as the biological landfill cover) and the transferring of plant outputs for recovery at other companies (RDF production). The average landfilling rate of waste after MBT is $45.9 \%(6.5 \%-69.2 \%)$.

\section{CONCLUSIONS}

In this paper an analysis of the selected MBT technology was presented. MBT technology can support waste management systems in its development towards circular economy targets. However, the existing plants need to be upgraded to reach higher recyclables and RDF recovery levels. The coarse fraction $>80 \mathrm{~mm}$ remaining after separation of recyclables and RDF does not meet the current landfill acceptance criteria. It should be recovered as low quality RDF fraction.

\section{References}

1. KPGO2022. National waste management plan 2022, Warszawa, 2016. Uchwała nr 88 Rady Ministrów z dnia 1 lipca 2016 r. (poz. 784)

2. GUS 2016, Environment protection, Warszawa

3. COM (2015) 595. Proposal for a Directive of the European Parliament and of the Council amending Directive 2008/98/EC on waste, Brussels, 2.12.2015

4. A. Jędrczak, E. den Boer, Final report of the 3rd stage of the study to carry out waste tests in 20 plants for mechanical and biological waste treatment, a study commissioned by The General Directorate for Environmental Protection, Zielona Góra (2015)

5. Dz.U. 2015 poz. 1277 regulation of the Minister of Economy of 16 July 2015 r. on the acceptance of waste to landfills 